\title{
Comparison of Plasma Atrial Natriuretic Peptide Levels in Healthy Children from Birth to Adolescence and in Children with Cardiac Diseases $^{1}$
}

\author{
J. WEIL, F. BIDLINGMAIER, C. DÖHLEMANN, U. KUHNLE, T. STROM, AND R. E. LANG \\ Department of Pediatrics, University of Munich, Munich, and Department of Pharmacology, University of \\ Heidelberg [REL], Heidelberg, Federal Republic of Germany
}

\begin{abstract}
An age-related dependence of plasma ANP levels was studied in 163 healthy children (94 boys, 69 girls) between the ages of day 1 and $16 \mathrm{yr}$. In neonates during the first 2-4 days of life, significantly higher plasma ANP plasma levels (range $129-356 \mathrm{pg} / \mathrm{ml}$, mean 227) were found compared with older infants and children $(p<0.001)$. Beyond the neonatal period through adolescence no significant difference in ANP concentrations could be found between the various age groups. Plasma ANP levels ranged between 2 and $109 \mathrm{pg} / \mathrm{ml}$ (mean 47) for all age groups after the newborn period. ANP levels were also determined in 15 adult volunteers and in arterial and venous cord blood of 16 healthy newborns, and concentrations were similar to those found in children. In addition, plasma ANP levels were measured in $\mathbf{4 0}$ children with various cardiac diseases; 22 of 40 patients exhibited ANP levels above the upper normal range seen in control children. Of these 22 patients all except two children revealed clinical signs of heart failure. In contrast 15 of 17 children without heart failure showed plasma ANP levels within the range of control children. ANP plasma levels ranged between 93 and 967 $\mathrm{pg} / \mathrm{ml}$ (mean 284) in patients with heart failure and between 15 and $118 \mathrm{pg} / \mathrm{ml}$ (mean 57) in patients without heart failure, respectively. Increased ANP levels in neonates and cardiac patients may result from increased atrial distention and reflect a compensatory mechanism to improve cardiac function by reducing pre- and afterload. (Pediatr Res 20: 1328-1331, 1986)
\end{abstract}

Abbreviation

ANP, atrial natriuretic peptide

Increasing evidence is available that the recently discovered peptide hormone, ANP, is involved in the regulation of water and electrolyte balance in humans (1).

The human bioactive peptide ( $\alpha$-ANP) is derived from higher molecular weight precursors $(6,000$ and 14,000 molecular weight,

Received February 25, 1986; accepted August 4, 1986.

Address for correspondence: Dr. Jochen Weil, Dr. v. Haunersches Kinderspital, Kinderklinik der Universität. Lindwurmstraße 4, D-8000 München 2, Federal Republic of Germany.

This study was supported by grants from the Deutschen Forschungsgemeinschaft (WE $1130 / 1-1$ )

'A part of this study was presented at the annual meeting of the European Society of Paediatric Research, Munich, FRG, October 14-17, 1985 (30). The measurement of plasma ANP levels in healthy children was part of the doctoral thesis of A. Hollizeck (31). termed $\beta$ - and $\gamma$-ANP, respectively) that are stored in specific granules in atrial cardiocytes $(2,3)$. The bioactive peptide (1-28 amino acids) has been shown to be released from these granules into the circulation and acts as a hormone on distant target organs such as kidney and vascular smooth muscle $(4,5)$. The sequence and genomic DNA of $\alpha-, \beta$-, and $\gamma$-ANP has been elucidated (6-9).

Recently, radioimmunoassay methods for the determination of ANP concentrations in human plasma have been developed The first studies reported increased plasma ANP levels in adult patients with heart failure $(10,11,21,24)$ or atrial tachycardia (12-14), and in adult volunteers after volume loading (15), compared with control subjects.

In children, however, few reports have been published. Increased ANP concentrations were determined in children with chronic renal failure, showing a positive correlation between the degree of volume expansion and the level of plasma ANP (16). In a short communication Lang and co-workers (17) reported higher plasma ANP levels in children with cardiopulmonary diseases versus control subjects.

The aim of our study was to look for an age dependent relationship of plasma ANP levels in healthy children from the perinatal period up to adolescence and to establish normal ranges for comparison of ANP concentrations found in children suffering from various cardiac diseases.

\section{SUBJECTS AND MATERIALS}

Control population. Plasma ANP levels were determined in 163 control children ( 94 boys, 69 girls) from birth to $16 \mathrm{yr}$ of age.

In 16 healthy term newborns (eight boys, eight girls) umbilical venous $(n=16)$ and arterial $(n=8)$ blood samples were taken after spontaneous vaginal delivery after early clamping of the cord. Birth weights varied between 2670 and $4440 \mathrm{~g}$ (mean 3510); the Apgar scores $1 \mathrm{~min}$ after birth was between 8 and 10 . In addition, 15 newborns aged 2-4 days were studied. Their weights ranged from 2510 to $4050 \mathrm{~g}$ (mean 3384 ). Venous blood was taken from samples drawn to rule out hyperbilirubinemia. In older children venous blood samples were collected before discharge from the hospital. These children were admitted for uncomplicated pediatric diseases such as mild upper respiratory tract infections, delayed puberty, obesity, motor and developmental disorders, social and behavioral problems, and neurological disorders such as facial nerve palsy and migraine. Children suffering from cardiovascular diseases or from fluid and electrolyte imbalances due to renal, gastrointestinal, and endocrine disorders were excluded (31). 
Furthermore, plasma ANP levels were studied in 15 healthy male volunteers aged 25-32 yr (mean $29.4 \mathrm{yr}$ ) and compared with levels found in control children.

Children with cardiac diseases. Forty children between 3 months and $14.5 \mathrm{yr}$ (mean $5.2 \mathrm{yr}$ ) were studied with various cardiac diseases. Among these patients were four children with cor pulmonale secondary to bronchopulmonary dysplasia, Northway stage IV (18), three children with tricuspid atresia, seven children with tetralogy of Fallot, five children with complete atrioventricular canal, seven children with ventricular septal defect, six children with atrial septal defect (secundum type), and eight children with heart failure due to other causes [congestive cardiomyopathy $(n=1)$, arteriovenous fistula $(n=1)$, patent ductus arteriosus $(n=1)$, endocardial fibroelastosis $(n=2)$, coarctation of the aorta with patent ductus arteriosus $(n=1)$, transposition of the great arteries with patent ductus arteriosus $(n=1)$, and transposition of the great arteries with tricuspid insufficiency after Mustard repair $(n=1)]$.

These diagnoses were established by cardiac catheterization ( $n$ $=28)$ and two-dimensional echocardiography $(n=12) ; 23$ of 40 patients exhibited clinical signs of cardiac failure such as increased heart and respiratory rates, hepatomegaly, failure to thrive, and cardiomegaly on a plain chest radiograph. All patients with heart failure were treated either with digitalis $(n=5)$ or with both digitalis and furosemide $(n=17)$.

In all patients and control children, blood for the ANP assay was taken during routine clinical blood sampling from peripheral veins. All infants and children were on a normal salt and fluid containing diet. Blood was collected between 0800 and $1000 \mathrm{~h}$. after normal feeding or breakfast, and all patients were supine for at least $15 \mathrm{~min}$. From all children consent was obtained by their parents. The study was approved by the ethical committee, Department of Pediatrics, University of Munich.

Methods. Blood samples were kept in chilled EDTA plastic tubes until separation of plasma by centrifugation at $4^{\circ} \mathrm{C} ; 1 \mathrm{ml}$ plasma was extracted by passing through $\mathrm{C}_{18}$ octadecylsilane cartridges according to the procedure described for rat plasma (19).

The recovery of synthetic $\alpha$-ANP was $70 \%$. Radioimmunoassay of ANP was performed using an antibody generated in New Zealand White rabbits immunized with human $\alpha$-ANP coupled to bovine thyreoglobulin. The standard buffer was 0.1 M Tris buffer, pH 7.4, containing $0.1 \%$ gelatin. ${ }^{125} \mathrm{I}$ human $\alpha$ ANP was used as a tracer (Amersham Buchler, Braunschweig, FRG), and synthetic human- $\alpha$ ANP (Bachem Ag, Bubendorf, Switzerland) was used to construct standard curves. Incubation was performed for $48 \mathrm{~h}$ at $4^{\circ} \mathrm{C}$. Bound and free ligands were separated by adding dextran-coated charcoal. By using this procedure, the lowest concentration of human ANP was $1.8 \mathrm{pg} /$ tube, yielding a binding significantly different from that in the absence of standard at the $95 \%$ confidence interval. The $50 \%$ intercept was $55.7 \mathrm{pg} /$ tube. The interassay variation was $14.5 \%$ $(n=6)$, the intraassay variation $6.2 \%(n=10)$. A complete cross reaction was observed with rat atrial peptide (28 amino acids) but not with rat atriopeptin III (Peninsula laboratories). Plasma values were not corrected for recovery.

Analysis of variance was used to determine significant differences between various age groups; $p<0.05$ was considered significant.

\section{RESULTS}

Healthy children. Figure 1 shows plasma ANP concentrations in healthy children from birth to adolescence and in healthy adult volunteers. In neonates during the first 2-4 days of life ANP levels (range 129-356, mean $227 \mathrm{pg} / \mathrm{ml}$ ) were significantly higher than levels found in infants through adolescents, adults, and in umbilical arterial and venous blood $(p<0.001)$. In addition, beyond the neonatal period in all other age groups tested there was no significant variation in ANP levels. In these age groups ANP levels were measured in a range between 2 and $109 \mathrm{pg} / \mathrm{ml}$ (mean $47 \pm 2 \mathrm{pg} / \mathrm{ml}$ SEM). There was no sex-related dependence of ANP concentrations seen in the infants and children studied (31).

Children with cardiac diseases. Figure 2 shows plasma ANP levels in children with various forms of cardiac disease; 22 of 40 patients exhibited ANP levels above the upper limit of concentrations found in control children; 20 of these 22 patients revealed clinical signs of heart failure; 17 of 40 children with cardiac disease showed no signs of heart failure. In 15 of these 17 patients without heart failure plasma ANP levels were measured within the range found in healthy individuals. In contrast, three children with cardiac failure showed ANP levels within the normal range. ANP plasma levels ranged between 93 and 967 $\mathrm{pg} / \mathrm{ml}$ (mean 284) in patients with heart failure and between 15 and $118 \mathrm{pg} / \mathrm{ml}$ (mean 57) in patients without heart failure.

\section{DISCUSSION}

In our study we attempted to establish a normal range of plasma ANP concentrations in healthy children from the early neonatal period up to adolescence. Our results clearly showed ANP concentrations in neonates significantly higher during the first 2-4 days of life than in older infants and children. To our knowledge no other studies have been published on plasma ANP levels in the human perinatal period.

The reason for the elevation of ANP plasma concentrations in neonates during the first 2-4 days of life is unclear. We speculate that these increased levels are due to the enormous changes occurring in the circulation after birth. Pulmonary arterial pressure in healthy human infants is greater than in adults up until 2 wk of life, the major decline occurring in the first 2-3 days after birth (20). In adult patients with congestive heart failure a positive correlation was reported between pulmonary arterial pressure and plasma ANP levels (21). Thus, the increased ANP levels in newborn infants may correlate with elevated pulmonary arterial pressure. Furthermore, left atrial pressure rises due to an increase in pulmonary venous return and in systemic resistance during the first days of life (20). Since there is increasing evidence that distension of right and left atrial wall may stimulate ANP release, the elevated ANP levels in our neonates could reflect changes in atrial pressure.

In newborn rats the ANP content of atrial extract, determined by a bioassay, has been reported to be significantly lower than in adult animals (22). However, circulating plasma ANP concentrations have not been determined by these investigators. It was speculated from these results that the compromised ability of newborn animals to excrete a sodium load is related to a deficiency of ANP (22). In view of our results it seems more likely that the reduced ANP content in atrial tissue during the neonatal period is caused by an enhanced ANP release from atrial granules into the circulation. This assumption is further supported by findings of De Bold (23), who demonstrated a diminished number of atrial granules in rat experiments after fluid challenge. Fluid challenge results in a marked increase of plasma ANP concentration in rats (19) and humans (15).

Furthermore, we found that cord arterial and venous ANP levels were similar in our newborns. One may conclude, therefore, that human placenta does not significantly degrade or remove ANP.

Beyond the neonatal period ANP plasma levels remained constant between 2 and $109 \mathrm{pg} / \mathrm{ml}$ (mean 47) with no apparent dependence on either age or sex. Other authors have also reported similar values in healthy adult volunteers. Studies done by Shenker et al. (24) and Yamaji et al. (25) reported mean ANP levels of $18.4 \mathrm{pmol} / \mathrm{liter}(56.6 \mathrm{pg} / \mathrm{ml})$ and $34.8 \mathrm{pg} / \mathrm{ml}$, respectively, whereas Tikkanen et al. (10) reported lower (mean 10.0 $\mathrm{pg} / \mathrm{ml}$ ) and Ogawa et al. (21) higher (mean $131 \mathrm{pg} / \mathrm{ml}$ ) plasma ANP concentrations. 


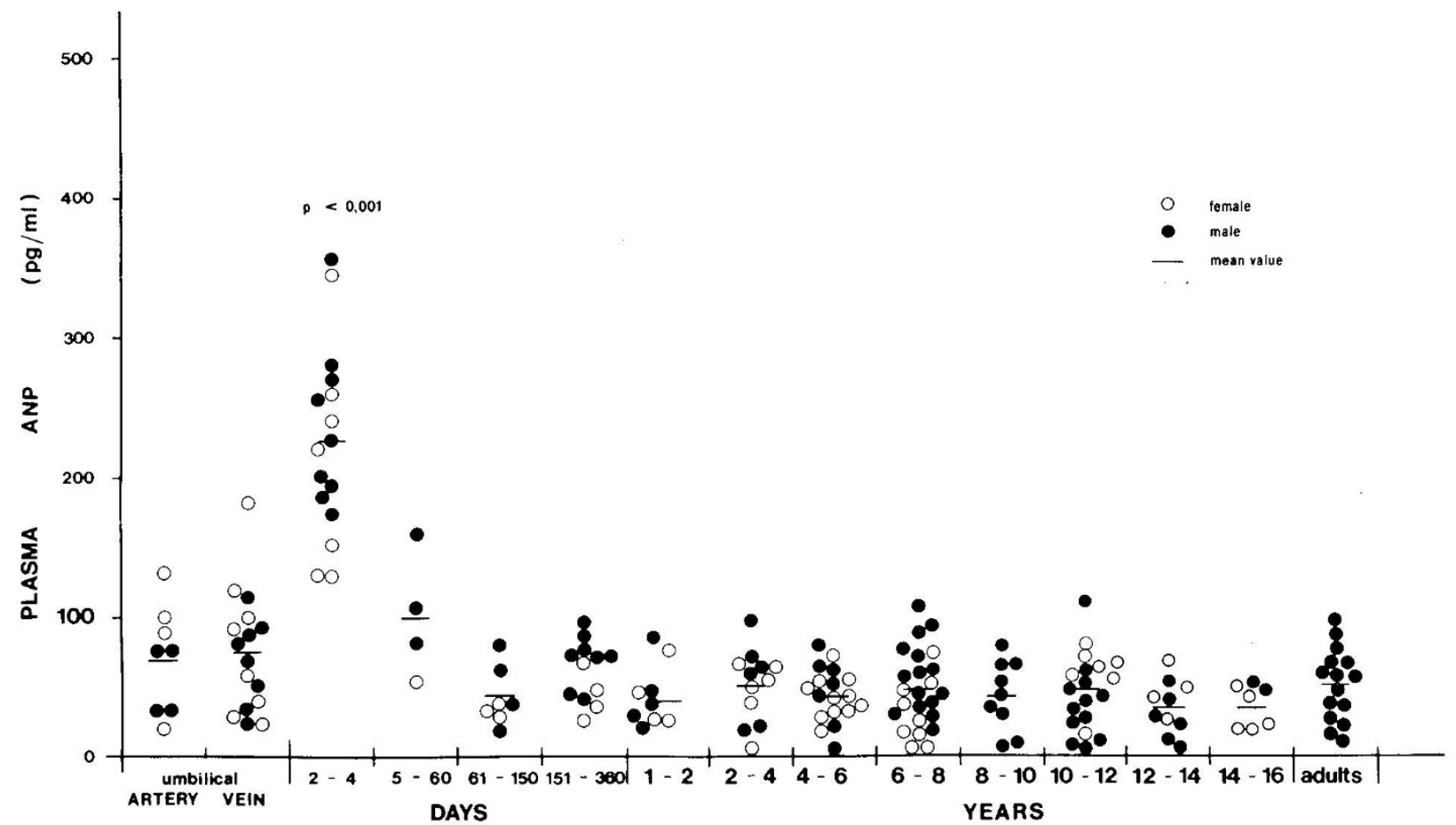

Fig. 1. Plasma ANP concentrations in healthy children from birth to adolescence and in healthy adult volunteers. In neonates aged $2-4$ days, ANP concentrations are significantly higher than in other age groups $(p<0.001)$.

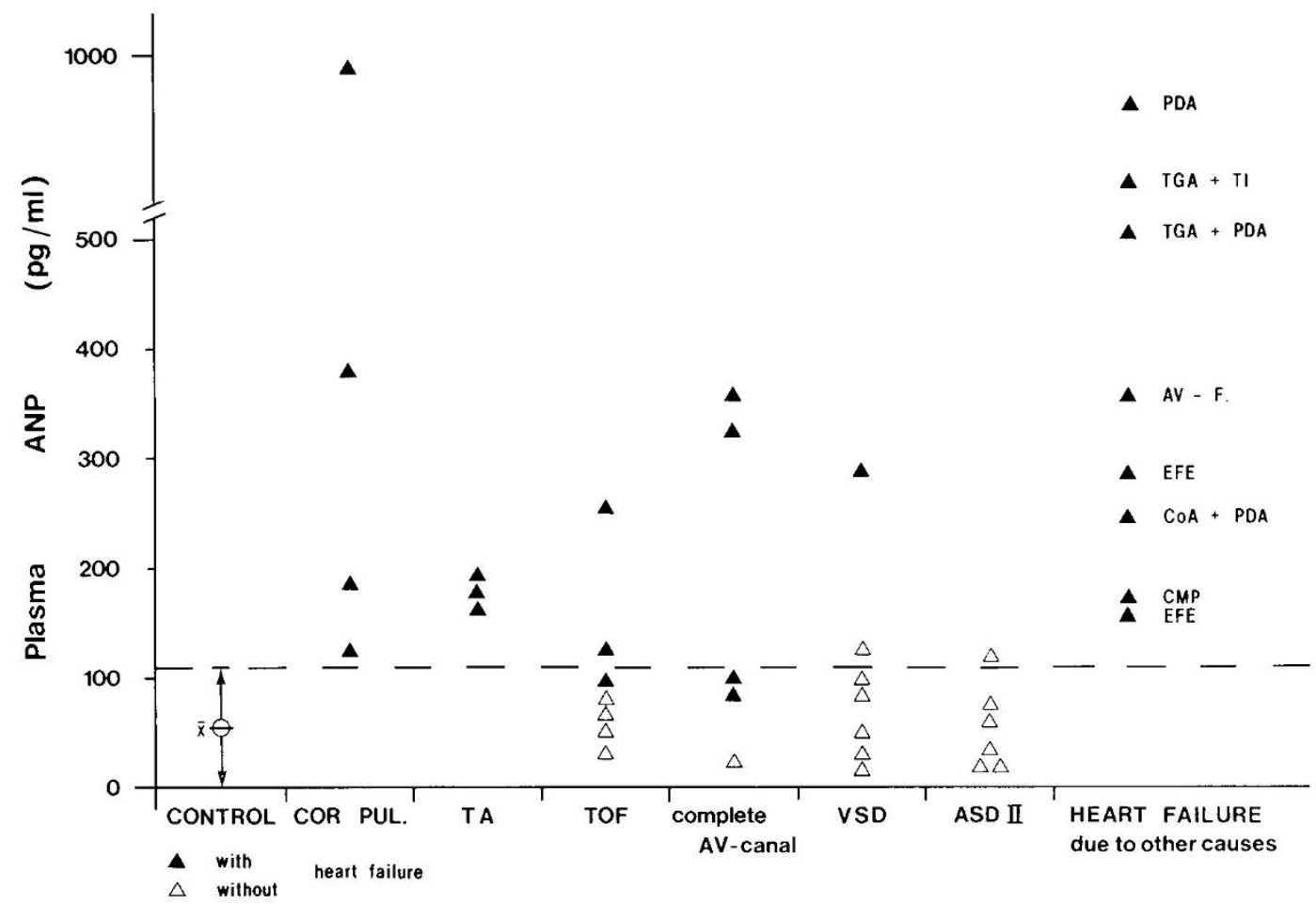

Fig. 2. Plasma ANP concentrations in children with various cardiac diseases (age 3 months and older). Broken line, upper range of control children beyond the neonatal period. Cor Pul, cor pulmonale; TA, tricuspid atresia; TOF, tetralogy of fallot; AV, atrioventricular; VSD, ventricular septal defect; ASD II, atrial septal defect (secundum type); PDA, patent ductus arteriosus botalli; TGA, transposition of great arteries; TI, tricuspid insufficiency; AV-F, arteriovenous fistula; EFE, endocardial fibroelastosis; CoA coarctation of aorta; CMP congestive cardiomyopathy.

In most children we studied with heart failure, elevated ANP levels were demonstrated compared with levels found in control children. Our results correlated with studies done in adults suffering from congestive heart failure, who also showed increased ANP plasma concentrations $(10,11,21,24)$. In these studies it is postulated that elevated levels of ANP are likely to be secondary to increases in atrial pressure. In our patients with cardiac diseases, hemodynamic parameters measured by cardiac catheterization were available only in a small number of children. We cannot explain, therefore, why children with an enlarged 
right atrium due to an atrial septal defect showed ANP levels within the normal range. Further studies are needed to elucidate the possible influence of atrial pressure on circulating ANP levels. Additionally, studies are necessary to investigate the effect of drugs such as diuretics on ANP release in children.

It has been shown that intravenous injection of ANP in humans results in a striking diuresis, natriuresis, and vasorelaxation $(10,26,27)$. Therefore, the observed high plasma ANP levels in heart failure may reflect a compensatory mechanism to reduce the pre- and afterload of the heart. However, fluid and sodium retention is a common feature in heart failure even in face of elevated ANP levels. The inability of high plasma ANP concentrations to provoke natriuresis and diuresis in these patients may be due to hemodynamic alterations such as decreased renal perfusion with elevated renin secretion (24). Recently, it has also been reported that the natriuretic response to ANP is markedly attenuated in dogs with acute experimental heart failure (28).

The cellular response to ANP may be diminished in patients with heart failure. Simultaneous measurement of plasma ANP and cyclic $3^{\prime}-5^{\prime}$-guanosine monophosphate, which is thought to be a mediator of the cellular effects of ANP $(15,27,29)$, may lead to a better understanding of ANP at the cellular level and its effects on diuresis.

Acknowledgments. The authors are grateful to B. Hoffmann, N. Lechner, S. Rode, A. Rüdisser, and B. Schramm for excellent technical assistance. They also thank A. Hollizeck for help in performing this study and S. Trapp for typing the manuscript.

\section{REFERENCES}

1. Laragh JH 1985 Atrial natriuretic hormone, the renin-aldosterone axis, and blood pressure-electrolyte homeostasis. N Engl J Med 313:1330-1340

2. Miyata A. Kangawa K, Toshimori T, Hatoh T, Matsuo H 1985 Molecular forms of atrial natriuretic polypeptides in mammalian tissues and plasma. Biochem Biophys Res Commun 129:248-255

3. De Bold AJ, Borenstein HB, Veress AT, Sonnenberg H 1981 A rapid and potent natriuretic response to intravenous injection of atrial myocardial extract in rats. Life Sci 28:89-94

4. Sugawara A Nakao K, Morii N, Sakamoto M, Suda M, Shimokura M, Kiso Y, Kihara M. Yamori Y Nishimura K, Soneda J, Ban T, Imura H $1985 \alpha$ Human atrial natriuretic polypeptide is released from the heart and circulates in the body. Biochem Biophys Res Commun 129:439-446

5. Ishihara T Aisaka K. Hattori K. Hamasaki S, Morita M, Noguchi T Kangawa K. Matsuo H 1985 Vasodilatory and diuretic actions of $\alpha$-human atrial natriuretic polypeptide ( $\alpha$-hANP). Life Sci 36:1205-1215

6. Kangawa K. Matsuo H 1984 Purification and complete amino acid sequence of $\alpha$-human atrial natriuretic polypeptide ( $\alpha$-hANP). Biochem Biophys Res Commun 118:131-139

7. Kangawa K. Fukuda A. Matsuo H 1985 Structural identification of $\beta$ - and $\gamma$ human atrial natriuretic polypeptides. Nature 131:397-400

8. Maki M, Paramentier M, Inagami T 1984 Cloning of genomic DNA for human atrial natriuretic factor. Biochem Biophys Res Commun 125:797-802
9. Oikawa S, Imai M, Ueno A, Tanaka S, Noguchi T, Nakazato H, Kangawa K, Fukuda A, Matsuo $\mathrm{H} 1984$ Cloning and sequence analysis of CDNA encoding a precursor for human atrial natriuretic polypeptide. Nature 309:724-726

10. Tikkanen L, Fyhrquist F, Metsärinne K, Leidenius R 1985 Plasma atrial natriuretic peptide in cardiac disease and during infusion in healthy volunteers. Lancet 2:66-69

11. Nakoaka H, Imataka K, Amano M, Fujii J, Ishibashi M, Yamaji T 1985 Plasma levels of atrial natriuretic factor in patients with congestive heart failure. N Engl J Med 313:892-893

12. Schiffrin EL, Gutkowska J, Kuchel O, Cantin M, Genest J, 1985 Plasma concentration of atrial natriuretic factor in a patient with paroxysmal atrial tachycardia. N Engl J Med 312:1196

13. Yamaji T, Ishibashi M, Nakaoka H, Imataka K, Amano M, Fujii J 1985 Possible role for atrial natriuretic peptide in polyuria associated with paroxysmal atrial arrhythmia. Lancet 1:1211

14. Tikkanen I, Metsärinne K, Fyhrquist F 1985 Atrial natriuretic peptide in paroxysmal supraventricular tachykardia. Lancet 2:40-41

15. Weil J, Lang RE, Suttmann H, Rampf U, Bidlingmaier F, Gerzer R 1985 Concomitant increase in plasma atrial natriuretic peptide and cyclic GMP during volume loading. Klin Wochenschr 63:1265-1268

16. Rascher W, Tulassay T, Lang RE 1985 Atrial natriuretic peptide in plasma of volume overloaded children with chronic renal failure. Lancet 2:303-305

17. Lang RE, Unger T, Ganten D, Weil J, Bidlingmaier F, Doehlemann C 1985 $\alpha$-Atrial natriuretic peptide concentrations in plasma of children with congential heart and pulmonary diseases. Br Med J 295:1241

18. Northway WH Jr, Rosan RC, Porter DY 1967 Pulmonary disease following respiratory therapy of hyaline-membrane disease: bronchopulmonary dysplasia. N Engl J Med 276:357-368

19. Lang RE, Thoelken H, Ganten D, Luft FC, Ruskoaho H, Unger Th 1985 Atrial natriuretic factor-a circulating hormone stimulated by volume loading. Nature 314:264-266

20. Rudolph AM 1970 The changes in the circulation after birth: their importance in congential heart disease. Circulation 61:343-359

21. Ogawa K, Ito T, Hashimoto H, Ito Y, Ohno O, Tsuboi H, Takasu N, Tanahash T, Satake T 1986 Plasma atrial natriuretic factor in congestive heart failure. Lancet 1:106

22. Pollock DM, Banks RO 1985 Lower atrial natriuretic activity in the newborn versus adult rat. Miner Electrolyte Metab 11:41-44

23. De Bold AJ 1979 Heart atria granularity effects of changes in water-electrolyte balance. Proc Soc Exp Biol Med 161:508-511

24. Shenker Y, Sider RS, Ostafin EA, Gerkin RJ 1985 Plasma levels of immunoreactive atrial natriuretic factor in healthy subjects and in patients with edema. J Clin Invest 76:1684-1687

25. Yamaji T, Ishibashi M, Takaku F 1985 Atrial natriuretic factor in human blood. J Clin Invest 76:1705-1709

26. Richards AM, Nicholls MG, Ikram H, Webster MWI, Yandle TG, Espinder EA 1985 Renal, haemodynamic and hormonal effects of human alpha atrial natriuretic peptide in healthy volunteers. Lancet 1:545-549

27. Gerzer R, Witzgall H, Tremblay J, Gutkowska J, Hamet P 1985 Rapid increase in plasma and urinary cyclic GMP after bolus injection of atrial natriuretic factor in man. J Clin Endocrinol Metab 61:1217-1219

28. Scriven TA, Burnett JC Jr 1985 Effects of synthetic atrial natriuretic peptide on renal function and renin release in acute experimental heart failure. Circulation 72:892-897

29. Hamet P, Tremblay J, Pang SC, Garcia R, Thibault G, Gutowska J, Cantin $M$, Genest J 1984 Effect of native and synthetic atrial natriuretic factor on cyclic GMP. Biochem Biophys Res Commun 123:515-527

30. Weil J, Bidlingmaier F, Döhlemann C, Knorr D, Kuhnle U, Vogel M, Lang RE 1985 Atrial natriuretic peptide in children-the heart as an endocrine organ. Pediatr Res 19:1073 (Abstr.)

31. Hollizeck A Measurement of plasma atrial natriuretic peptide levels in healthy children from birth to adolescence. Doctoral thesis, Faculty of Medicine, University of Munich (FRG) 